\title{
Culturally Responsive Teaching Knowledge and Practices of Online Faculty
}

\author{
Keri L. Heitner \\ Center for Educational and Instructional Research \\ School of Advanced Studies \\ University of Phoenix \\ Miranda Jennings \\ Northcentral University
}

\begin{abstract}
Cultural differences between faculty and their students can create important challenges that affect the quality and efficacy of online teaching and learning. The objectives of this study were to: (a) create and pilot test an assessment for online faculty to measure culturally responsive teaching knowledge (CRT) and culturally responsive educational practices (CREP) in teaching and advising students of color, military students, LGBTQ students, religious minority students, and international students; (b) describe participants' CRT knowledge, value, and CREP; and (c) examine differences between their knowledge and their practices. The combined pilot and main study sample was comprised of 47 completed surveys. Internal consistency reliability was high for all subscales (.895-.970); subscale intra-class correlation coefficients ranged from .526-.833. The pilot round revealed strong face and content validity. Campbell-Fiske multitraitmultimethod matrix generated evidence of construct validity. Within-group comparisons of subscale scores using Wilcoxon Signed-ranks test revealed some significant differences between perceived knowledge and practice. Mann Whitney $U$ test did not reveal significant differences in subscale scores or overall score by sector, degree level taught, or gender. The results have important implications for faculty training, professional development, mentoring, and support. Faculty who teach online who understand and value culturally responsive pedagogy and have the knowledge and skills to implement best practices in meeting the needs of diverse learners will enhance both teaching and learning. Culturally responsive knowledges and practice are particularly important as online programs are becoming ubiquitous across traditional institutions of higher education and their core faculty are teaching an increasingly diverse student body.
\end{abstract}

Keywords: Cultural responsiveness; culturally responsive teaching; culturally responsive educational practices; online teaching 


\section{Introduction}

Faculty, and the students they teach in the online environment, often come from different worlds, whether social, ethnic, cultural, geographical, or otherwise contextually different. In the online environment, faculty typically act as facilitators of learning, much of which takes place through asynchronous social interaction and networking with the instructor and classmates. Students are active participants in the online classroom. Cultural differences between faculty and their students can pose important challenges that affect the quality and efficacy of teaching and learning (Gay, 2013). For example, a lack of understanding about culturally responsive issues and practices to meet the needs and expectations of online students can lead to miscommunication, mistrust, poor guidance, frustration, attrition, and delayed program completion. These issues may be exacerbated in the online classroom due to the nature of faculty/student interaction, the asynchronous nature of the instruction, the broad cultural and geographic diversity of the student body, and the lack of visual cues in the interactions.

Faculty can bridge cultural differences through culturally responsive teaching (Gay, 2010). Cultural responsiveness in teaching is an important component of meeting the needs of diverse students (Gay, 2010) and in engaging diverse students in higher education, including students of color; military students; lesbian, gay, bisexual, transgender, and questioning (LGBTQ) students; religious minority students; and international students (Harper \& Quaye, 2010). Many higher education institutions across various higher education sectors educate an increasingly diverse body of non-traditional students, served by a body of faculty that largely reflects the majority culture, although is becoming more diverse. Cultural responsiveness is an imperative for meeting the needs of these students.

A review of the literature revealed that little is known about the culturally responsive teaching knowledge and practices of the majority of online faculty members who teach students and serve as thesis and dissertation advisors for students of color, LGBTQ students, religious minority students, and international students. Knowledge gaps include the extent to which online faculty members are aware of these issues and consider them in their work, the extent to which they value and apply culturally responsive practices, what skills they think they have, and what skills they perceive they are lacking. Knowledge gaps also include whether cultural responsiveness knowledge and culturally responsive practices differ by education sector and degree level taught. These knowledge gaps must be addressed in order to provide adequate professional development and support for online faculty who teach diverse students.

A quantitative descriptive comparative design was applied to: (a) create and pilot test an assessment for online faculty to measure culturally responsive teaching knowledge (CRT) and culturally responsive educational practices (CREP) in teaching and advising students of color, military students, LGBTQ students, religious minority students, and international students; (b) describe respondents' CRT knowledge, value, and CREP; and (c) examine differences between their knowledge and practices. The findings may have implications for instructors teaching asynchronously across multiple geographic locations and diverse cultural backgrounds. The findings may have important implications for online faculty training, professional development, mentoring, and support. 
A review of the pertinent literature sets the context for the current study, followed by the research questions and hypotheses tested. Other sections include population and sampling, method, and results. The article concludes with a discussion of the findings and the conclusion.

\section{Literature Review}

The research was supported by a theoretical and conceptual approach known as Culturally Responsive Pedagogy or Culturally Responsive Teaching (Banks, 2008; Gay, 2010, 2013; Ladson-Billings, 1995). A core tenet of culturally responsive teaching is creating equal opportunity for academic success for students from diverse cultural backgrounds (Banks, 2008; Gay, 2010, 2013; Ladson-Billings, 1995). Another tenet is acknowledging students' diverse backgrounds, prior knowledge, learning preferences, and experiences to enhance the process of teaching and learning (Siwatu, 2007). Culturally responsive teaching necessitates that instructors develop additional competence in instruction and assessment (Banks, 2008; Gay, 2010; LadsonBillings, 2008). Drivers of culturally responsive education are acknowledging, valuing, and using students' cultural backgrounds and cultural identities as conduits for building environments optimal for learning (Gay, 2010; Nieto, 1999). Research has demonstrated the positive benefits of strengthening connections between diverse communities to foster better teaching and enhance learning (Gurin, Day, Hurtado, \& Gurin, 2002; Jabbar \& Hardaker, 2013; Villegas \& Lucas, 2009).

In order to meet the needs of diverse students, instructors must recognize the importance of identity, language, and culture in shaping how students learn (Guerra, 2006) and informing pedagogy (Banks, 2016). Engaging in culturally responsive teaching means valuing cultural differences; challenging stereotypes, racism, prejudice, oppression, intolerance, and injustice; using cultural knowledge to guide pedagogy; mediating classroom inequities in power stemming from culture, class, race, and other disparities; and embracing cultural responsiveness as integral to educational effectiveness for all students (Gay, 2010). Villegas and Lucas (2002) proposed six salient characteristics of culturally responsive teachers at the K-12 level. Culturally responsive teachers should be (a) socio-culturally conscious, (b) have an attitude that is diversity-affirming, (c) see themselves as change agents, (d) understand how students construct knowledge and how to promote it, (e) strive to learn about their students' lives, and (f) use this knowledge to build on what students already know while expanding their horizons (Villegas \& Lucas, 2002).

Higher education faculty tend to be less aware of culturally responsive pedagogy than their counterparts in K-12 education (Ginsburg \& Wlodkowski, 2009), as most of the published literature on culturally responsive pedagogy has focused on K-12 and K-12 teacher training. Jabbar and Hardaker (2015) drew upon the salient characteristics of culturally responsive teachers (Villegas \& Lucas, 2002) and the five essential elements of engaging in culturally responsive teaching (Gay, 2010), adapting them within a theoretical framework for culturally responsive teaching applicable to British university business schools. The adapted theoretical framework consists of five pillars: (a) cultural consciousness, (b) resources, (c) moral responsibility, (d) cultural bridging, and (e) higher education curriculum (Jabbar \& Hardaker, 2015). Using this framework, Jabbar and Hardaker interviewed British university business school faculty about their perceptions of various components of culturally responsive teaching. 
Baldwin (2015) examined the importance and benefits of culturally responsive pedagogy in serving multicultural communities in the Christian college setting.

Han et al. (2014) conducted a collaborative self-study of how seven teacher educators (early childhood education, elementary education, secondary education, educational leadership, and school counseling) defined, enacted, and navigated their roles as culturally responsive higher educators. The finding revealed that the participants struggled to define culturally responsive pedagogy (CRP) in higher education. The findings also revealed that the participants valued modeling and building relationships with students when using CRP; tensions that arose with students and the institutions themselves, and opportunities for continuous professional and personal development.

Recent research, based on publicly available archival data, suggests that career colleges out-performed other colleges in graduating students from racial and ethnic minority backgrounds (Heitner \& Sherman, 2013). Career colleges successful at enrolling, retaining, and/or graduating students from one racial or ethnic minority group appear to be beneficial for students belonging to other racial or ethnic minority groups (Heitner \& Sherman, 2013). A study about race in cross-race advising relationships between White faculty and Black doctoral students support more and earlier professional development for faculty advisors (Barker, 2011).

Students, particularly students of color and women, valued having a mentor of the same race or gender (Blake-Beard, Bayne, Crosby, \& Muller, 2011). To succeed in primarily White higher education institutions, faculty must provide African American male students with adequate validation and support (Wood \& Palmer, 2016). African American students' perceptions of faculty behavior and faculty advising and the lack of diverse faculty leadership complicate their degree completion (Felder, 2010). Interest convergence is an important feature of the advising relationship between African American doctoral students and their faculty member or advisor, made more complex by differences in their race (Felder \& Barker, 2013). Faculty must consider the ways African American students navigate the historical weight of exclusionary institutional environments and how these climates shape how students perceive interactions with faculty in order to develop a culturally responsive advising approach (Felder \& Barker, 2014).

Military learners have a greater reliance on online and for-profit universities when compared to traditional learners (Ford \& Vignare, 2014), and are increasingly choosing educational options that include online learning (Allen \& Seaman, 2011, 2013). Online faculty need to understand cultural issues unique to military learners, who comprise a minority culture in the online classroom (Starr-Glass, 2014).

Military learners typically exhibit and are characterized by high levels of motivation and autonomous learning (Starr-Glass, 2011). Military learners typically have held positions of higher responsibility and have more extensive work experience, greater self-discipline, higher leadership abilities, more maturity, and a more purposeful focus than nonmilitary learners of the same age (Starr-Glass, 2011; Steele, Salcedo, \& Coley, 2010). Many military learners have traveled widely and have built an understanding of different cultures (Starr-Glass, 2011). 
Based on the unique characteristics of military learners, Starr-Glass (2014) proposed rules of engagement for higher education faculty working with military learners. Multicultural competence is imperative in serving the distinct cultural group of student veterans and service members (SVSM) (Arminio, Grabosky, \& Lang, 2016). Military cultural responsiveness pertains to having the appropriate knowledge, skills, and attitudes needed to serve the veteran population and their families effectively (Gleeson \& Hemmer, 2014). Facilitators for success of SVSM in higher education include offering regular opportunities for professional development of faculty regarding serving SVSM (Arminio et al., 2016).

To measure the impact of training to increase military cultural competency (MCC), Cate and Albright (2014) developed five items to measure MCC in a higher education setting. These measures indicated that the training yielded significant long-term increases in higher education faculty, administrator, and staff military cultural competency (Cate \& Albright, 2014). While research literature about military learners has revealed the importance of a sense of institutional belonging, research is sparse in terms of a specific focus on the realities, experiences, and fit for online military learners (Ford \& Vignare, 2014).

Religious minority students' experiences in higher education may have a negative effect on their retention (Mutakabbir \& Nuriddin, 2016). Challenges they may face in the classroom include a Eurocentric curriculum (Mutakabbir \& Nuriddin, 2016). Muslim students may face threats, harassment, and student intimidation (Mutakabbir \& Nuriddin, 2016).

Sadykova and Dautermann (2009) examined issues and practices for institutions involved in cross-border or cross-cultural online education, focusing on four domains - the host institution, technology, learning models of students, and teaching models of faculty. Timely, regular feedback that is understandable and applicable is an essential component of productive communication between the faculty member and the student (Sadykova \& Dautermann, 2009). Students' perceived barriers affected the quality of online discussions between students from distinct cultures who share a common language (Olesova, Yang, \& Richardson, 2011).

The purpose of the quantitative comparative study was to create and pilot test an assessment instrument for online faculty members designed to measure culturally responsive teaching knowledge and culturally responsive practices in teaching and advising students of color, military students, LGBTQ students, religious minority students, and international students. The purpose was also to examine the level of and differences in cultural responsiveness knowledge and culturally responsive practices.

The first three research questions were descriptive: R1: To what extent are online faculty knowledgeable about culturally responsive teaching (CRT)? R2: To what extent do online faculty value culturally responsive teaching? R3: To what extent do online faculty use culturally responsive educational practices (CREP)?

The fourth research question pertained to within-group comparisons of subscale scores for knowledge, value/importance, practice, and preparation/skills. The following null hypotheses were tested: 
H10: Scores for Value/Importance of CRT are higher than scores for Knowledge of CRT.

H2o: Scores for Knowledge of CRT are higher than scores for Knowledge (about meeting needs) of Different Communities.

H3o: Scores for Knowledge of CRT are higher than scores for Value (about meeting needs) of Different Communities.

H4o: Scores for Value/Importance of CRT are higher than scores for Value (about meeting needs) of Different Communities.

H5o: Scores for Use of CRT are higher than scores for Practice (meeting needs) of Different Communities.

H6o: Scores for Prep/Skills for CREP are higher than scores for Knowledge/Skills/ Abilities (for meeting needs) of Different Communities.

The fifth research question pertained to between-group differences in subscale and overall scores by sector, degree level taught, and gender. The sample was too small to examine differences by other demographic variables. The following null hypotheses were tested:

H7o: No differences exist between for-profit and not-for-profit education online faculty in their knowledge about, value of, and use of culturally responsive teaching. H8o: No differences exist between undergraduate and graduate-level online faculty in their knowledge about, value of, and use of culturally responsive teaching.

H9o: No differences exist between male and female online faculty in their knowledge about, value of, and use of culturally responsive teaching.

\section{Method}

The study involved applying a quantitative method and a descriptive comparative research design. Given the complexity of developing and evaluating evidence of reliability and validity of a new instrument to assess culturally responsive teaching practices, restricting the research to application of a quantitative method was appropriate to the research goals. The study was approved by the University of Phoenix Institutional Review Board in 2015. The first phase was creating and piloting an assessment instrument for online faculty members designed to measure their knowledge and value of culturally responsive teaching and their use of culturally responsive practices in teaching and advising students of color, military students, LGBTQ students, religious minority students, and international students. The second phase involved administering the instrument via SurveyMonkey Pro to a larger sample of online faculty to identify their culturally responsive teaching knowledge and practice and examine differences in knowledge about and value of culturally responsive teaching and use of culturally responsive practices by education sector and degree level taught. A description of the population/sampling, data collection/instrumentation, and data analysis procedures follows.

\section{Study Population/Sampling}

The study setting was online higher education, whether in the public, not-for-profit sector, the private, not-for-profit sector, or the career college/for-profit sector. Targeting online faculty across the for-profit and not-for-profit sectors (both public and private, regardless of 
institutional focus and mission) at the undergraduate and graduate (master's and doctoral) levels supported two separate between-group comparisons, the first by educational sector, and the second by level of education taught.

Purposive sampling was used to select the sample, supplemented by snowball sampling. The first sampling criterion was at least two years of online instructional experience at either the undergraduate or the graduate level. The second criterion was prior experience teaching at least five courses delivered fully online. These criteria reflected experience necessary to respond to the survey questions. Participant screening occurred following receipt of online informed consent via SurveyMonkey Pro.

Information about the pilot data collection phase was disseminated through word of mouth and postings on the PI's social media page. Information about the main study was disseminated through word of mouth, through announcements in professional listservs and social media groups pertinent to online education, and through internal email announcements to faculty at two institutions, a 2-year public community college, and a state college, where permission was obtained to solicit subjects. No information was collected about respondents' affiliation apart from the sector in which and the level of education at which the respondents teach.

While more than 80 surveys were submitted, many were incomplete and therefore removed from the analysis. As the instrument was still under development, we did not require that participants answer a given question in order to proceed to the next question. Given that the pilot phase of administering the instrument did not result in any substantive changes to the instrument, we combined the pilot sample with the main study sample. The resultant sample size, $\mathrm{N}=47$, was sufficient to support one-tailed within-group comparisons with adequate power (.95) and a large effect size. (.5). The resultant sample size was inadequate for two-group two-tailed comparisons. The resultant sample was too small to support a three-way comparison by forprofit, not-for-profit-public, and not-for-profit-private.

\section{Sample Characteristics}

Of the 47 combined pilot and main study participants, all but $17.0 \%$ answered demographic questions. The main study sample was fairly well balanced in terms of the primary teaching sector of the participants. More than $42 \%$ of participants reported teaching at not-forprofit public institutions; $17.0 \%$ taught at not-for-profit private institutions. Just over 35\% reported teaching in for-profit educational institutions, a career college, or a technical school; 4.3\% taught in a military or corporate setting. Participants reported teaching at the undergraduate (83.0\%), master’s (44.7\%), and doctoral (34.0\%) levels.

The majority of participants had extensive online teaching experience. Under a third (29.8\%) taught for 6-10 years, and more than a quarter (25.5\%) taught online for more than 10 years. Just over a quarter (27.7\%) of participants taught online for $2-5$ years. More than $70 \%$ taught more than 10 online classes; $61.7 \%$ had taught more than 15 classes online. Just 12.8\% taught between 5-10 online classes. 
More than half of the participants (51.1\%) reported their gender identity as female; $29.8 \%$ reported their gender identity as male. More than half (53.2\%) were 55 or older. Almost three quarters (74.5\%) were age 45 or older. Almost a quarter (23.4\%) reported being a member of a racial, ethnic, or linguistic minority group. Slightly over 2\% identified as LGBTQ.

\section{Instrumentation and Data Collection}

The instrument created for the study is comprised of statements rated on a 5-point Likerttype scale (see Table 1; a copy of the instrument appears under Appendices). The instrument focuses on awareness of these issues, the extent to which online faculty consider, value, and address culturally responsive teaching in their work. The instrument is based on and informed by the principles and tenets of Culturally Responsive Teaching (Banks, 2008; Gay, 2010, 2013; Ladson-Billings, 1995).

Table 1 Questions, Items, and Scales

\begin{tabular}{|c|c|}
\hline Question/Items & Scale \\
\hline $\begin{array}{l}\text { 1.1-1.12: Knowledge } \\
\text { responsive teaching }\end{array}$ & $\begin{array}{l}\text { 1-Poor; 2- Fair; 3- Good; 4-Very good; 5- } \\
\text { Excellent }\end{array}$ \\
\hline $\begin{array}{l}\text { 2.1-2.12 Value/importance of culturally } \\
\text { responsive teaching }\end{array}$ & $\begin{array}{l}\text { 1-Not at all important; 2- Slightly important; } 3- \\
\text { Somewhat important; 4-Very important; } \\
\text { Extremely important }\end{array}$ \\
\hline $\begin{array}{l}\text { 3.1-3.12: Use of culturally responsive } \\
\text { educational practices }\end{array}$ & $\begin{array}{l}\text { 1-Never; 2- Rarely; 3- Occasionally; } \\
\text { Frequently; 5-All the time. }\end{array}$ \\
\hline $\begin{array}{l}\text { 4.1-4.12: Preparation/skills to use } \\
\text { culturally responsive educational practices }\end{array}$ & $\begin{array}{l}\text { 1-Poor; 2- Fair; 3- Good; 4-Very good; 5- } \\
\text { Excellent }\end{array}$ \\
\hline $\begin{array}{l}\text { 5.1-5.7: Knowledge re: Meeting the needs } \\
\text { of different communities of students }\end{array}$ & $\begin{array}{l}\text { 1-Strongly Disagree; 2- Disagree; 3- Unsure; 4- } \\
\text { Agree; 5-Strongly agree }\end{array}$ \\
\hline $\begin{array}{l}\text { 5.8-5.14: Value re: Meeting the needs of } \\
\text { different communities of students }\end{array}$ & $\begin{array}{l}\text { 1-Strongly Disagree; 2- Disagree; 3- Unsure; 4- } \\
\text { Agree; 5-Strongly agree }\end{array}$ \\
\hline $\begin{array}{l}\text { 5.15-5.21: Practice re: Meeting the needs } \\
\text { of different communities of students }\end{array}$ & $\begin{array}{l}\text { 1-Strongly Disagree; 2- Disagree; 3- Unsure; 4- } \\
\text { Agree; 5-Strongly agree }\end{array}$ \\
\hline $\begin{array}{l}\text { 5.22-5.28: KSAs for Meeting the needs of } \\
\text { different communities of students }\end{array}$ & $\begin{array}{l}\text { 1-Strongly Disagree; 2- Disagree; 3- Unsure; 4- } \\
\text { Agree; 5-Strongly agree }\end{array}$ \\
\hline
\end{tabular}


The instrument was validated for test content by a panel of 10 faculty and former students representing minority (racial, ethnic, religious), military; LGBTQ; and international cultures, who reviewed the items and the scales for clarity and relevance. Evidence of content validity was also assessed based on response processes via four interviews following instrument completion and face validation. The only change made was combining the two screening questions into a single question.

Examining the instrument created for the study for evidence of reliability and construct validity involved using Cronbach's alpha analysis and the Campbell-Fiske multitraitmultimethod matrix analysis (Campbell \& Fiske, 1959) to examine convergent and discriminant validity. Calculating Cronbach's alpha using the main study responses for each of the subscales generated evidence of the internal consistency reliability of the instrument. Cronbach's alpha was calculated within each separate set of items, which focused on a particular construct and were rated on the same Likert-type response scale for that particular question group. Because the current study involved an attempt to examine faculty perceptions on an instrument with several different Likert-type scales, using Cronbach's alpha to examine evidence of internal consistency for each of the subsections and overall was appropriate.

Calculating the average correlation between items on the survey instrument revealed evidence of high internal consistency reliability. Intra-class correlations show good evidence of inter-rater agreement. Internal consistency reliability was high for all subscales (.895-.970); subscale intra-class correlation coefficients ranged from .526-.833. Evidence of internal consistency reliability and intra-class correlation is presented in Table 2.

Table 2

Internal Consistency Reliability

\begin{tabular}{|c|c|c|}
\hline Question/Items & $\begin{array}{l}\text { Cronbach's } \\
\text { alpha }\end{array}$ & $\begin{array}{l}\text { Intraclass } \\
\text { correlation }\end{array}$ \\
\hline $\begin{array}{l}\text { 1.1-1.12: Knowledge about culturally responsive } \\
\text { teaching }\end{array}$ & .959 & .650 \\
\hline $\begin{array}{l}\text { 2.1-2.12 Value/importance of culturally } \\
\text { responsive teaching }\end{array}$ & .970 & .726 \\
\hline $\begin{array}{l}\text { 3.1-3.12: Use of culturally responsive educational } \\
\text { practices }\end{array}$ & .956 & .630 \\
\hline $\begin{array}{l}\text { 4.1-4.12: Preparation/skills to use culturally } \\
\text { responsive educational practices }\end{array}$ & .961 & .664 \\
\hline $\begin{array}{l}\text { 5.1-5.7: Knowledge re: Meeting the needs of } \\
\text { different communities of students }\end{array}$ & .902 & .552 \\
\hline $\begin{array}{l}\text { 5.8-5.14: Value re: Meeting the needs of different } \\
\text { communities of students }\end{array}$ & .982 & .833 \\
\hline $\begin{array}{l}\text { 5.15-5.21: Practice re: Meeting the needs of } \\
\text { different communities of students }\end{array}$ & .957 & .748 \\
\hline
\end{tabular}


5.22-5.28: KSAs for meeting the needs of .895 .536 different communities of students

The intra-class correlation coefficient indicates agreement between and within raters. Given the various communities and constructs covered across several different items and scales, low overall intra-class reliability provides verification of participants' varying perceived knowledge and practices within and across raters.

The Campbell-Fiske multitrait-multimethod matrix analysis was used to examine the construct validity of the survey instrument by assessing the main study data for convergent and discriminant validity. The survey measured online faculty perceptions of several constructs pertaining to culturally responsive teaching knowledge and culturally responsive educational practices in teaching and advising students of color, military students, LGBTQ students, religious minority students, and international students, which were multiple traits. The multiple methods were the distinct groups of respondents, who in this study were the faculty from the private, not-for-profit, public, and for-profit sectors who completed the survey instrument. Campbell-Fiske multitrait-multimethod matrix was used to evaluate evidence of construct validity of survey instrument by correlating the responses to the same groups of questions across respondents and identifying statistically significant correlations between the subscale scores. The subscale score correlation matrix appears in Table 3. 
Table 3

Subscale Score Correlation Matrix

\begin{tabular}{|c|c|c|c|c|c|c|c|c|c|}
\hline & $\begin{array}{l}\text { S1 } \\
\text { Know } \\
\text { CRT }\end{array}$ & $\begin{array}{l}\text { S2 } \\
\text { Val/ } \\
\text { Imp } \\
\text { CRT }\end{array}$ & $\begin{array}{l}\text { S3 } \\
\text { Use of } \\
\text { CREP }\end{array}$ & $\begin{array}{l}\text { S4 } \\
\text { Prep/ } \\
\text { skills for } \\
\text { CREP }\end{array}$ & $\begin{array}{l}\text { S5 } \\
\text { Dif } \\
\text { Com } \\
\text { Know }\end{array}$ & $\begin{array}{l}\text { S5 } \\
\text { Dif } \\
\text { Com } \\
\text { Val }\end{array}$ & $\begin{array}{l}\text { S5 } \\
\text { Dif } \\
\text { Com } \\
\text { Pract }\end{array}$ & $\begin{array}{l}\text { S5 } \\
\text { Dif } \\
\text { Com } \\
\text { KSAs }\end{array}$ & $\begin{array}{l}\text { S5 } \\
\text { Dif } \\
\text { Com } \\
\text { Sum }\end{array}$ \\
\hline \multicolumn{10}{|l|}{ Know } \\
\hline CRT & 1 & & & & & & & & \\
\hline$N$ & - & & & & & & & & \\
\hline$P$ & - & & & & & & & & \\
\hline \multicolumn{10}{|c|}{ Val/Imp } \\
\hline CRT & .493 & 1 & & & & & & & \\
\hline$N$ & 47 & - & & & & & & & \\
\hline$P$ & .00 & - & & & & & & & \\
\hline \multicolumn{10}{|c|}{ Use of } \\
\hline CREP & .686 & .845 & 1 & & & & & & \\
\hline$N$ & 47 & 47 & - & & & & & & \\
\hline$P$ & .00 & .00 & - & & & & & & \\
\hline \multicolumn{10}{|c|}{ Prep/skill } \\
\hline $\mathrm{s}$ & & & & & & & & & \\
\hline CREP & .725 & .263 & .440 & 1 & & & & & \\
\hline$n$ & 42 & 42 & 42 & - & & & & & \\
\hline$P$ & .00 & .09 & .00 & - & & & & & \\
\hline \multicolumn{10}{|c|}{ DifCom } \\
\hline Know & .586 & .184 & .365 & .760 & 1 & & & & \\
\hline$n$ & 41 & 41 & 41 & 41 & - & & & & \\
\hline$P$ & .00 & .25 & .02 & .00 & - & & & & \\
\hline \multicolumn{10}{|c|}{ DifCom } \\
\hline Val & .263 & .882 & .789 & .115 & .215 & 1 & & & \\
\hline$n$ & 40 & 40 & 40 & 40 & 40 & - & & & \\
\hline$P$ & .10 & .00 & .00 & .48 & .18 & - & & & \\
\hline \multicolumn{10}{|c|}{ DifCom } \\
\hline Pract & .322 & .726 & .800 & .286 & .377 & .771 & 1 & & \\
\hline$n$ & 40 & 40 & 40 & 40 & 40 & 40 & - & & \\
\hline$P$ & .04 & .00 & .00 & .07 & .02 & .00 & - & & \\
\hline \multicolumn{10}{|c|}{ DifCom } \\
\hline KSAs & .573 & .077 & .278 & .680 & .784 & .085 & .399 & 1 & \\
\hline$n$ & 40 & 40 & 40 & 40 & 40 & 40 & 40 & - & \\
\hline$P$ & .00 & .64 & .08 & .00 & .00 & .60 & .01 & - & \\
\hline \multicolumn{10}{|c|}{ DifCom } \\
\hline Sum & .555 & .654 & .760 & .575 & .748 & .726 & .862 & .699 & 1 \\
\hline$n$ & 40 & 40 & 40 & 40 & 40 & 40 & 40 & 40 & - \\
\hline$P$ & .00 & .00 & .00 & .00 & .00 & .00 & .00 & .00 & - \\
\hline
\end{tabular}

Note: bolded correlation coefficients are significant at $p<.05$. 
We administered the instrument via SurveyMonkey Pro to a pilot sample of online faculty as Phase II of the validation. Eighteen surveys were submitted. We then administered the instrument to the main study sample. Data collection occurred during the 2015-2016 fall and spring semesters. Demographic information was also collected via the instrument, as reported under Sample Characteristics.

The dependent variables we compared within and between groups included knowledge about different aspects of culturally responsive teaching, perceived value of culturally responsive teaching, and various culturally responsive teaching practices. The independent variables for the between-group comparisons were education sector, higher education level taught, and gender.

\section{Data Analysis}

Data analysis involved three stages: descriptive statistics, assessment of normality, and within-group and between-group comparisons. First, we used frequency counts and percentages to describe the sample. Next, we calculated the mean, median, mode, range, and standard deviation for the subscale scores. We assessed skewness and kurtosis to determine the distribution of the data. Given that none of the dependent variables was normally distributed, we used Wilcoxon Signed-ranks test for within group comparisons of subscale scores and Mann Whitney $\mathrm{U}$ test for between group comparisons.

\section{Results}

A summary of aggregate descriptive statistics for the responses to the subscales and overall scores on the instrument appears in Table 4. A Wilcoxon Signed-ranks test for H1o indicated higher scores for Value/Importance of CRT $(\mathrm{Mdn}=55)$ than for Knowledge of CRT $(\mathrm{Mdn}=50), \mathrm{Z}=2.82, \mathrm{p}<.05, \mathrm{r}=.29$, one-tailed. H1o was rejected. The other median subscale scores for sections 1-4 were not significantly different from each other. A Wilcoxon Signedranks test indicated higher scores for Knowledge of CRT ( $\mathrm{Mdn}=51.5)$ than for Knowledge (about meeting needs) of Different Communities (Mdn $=29$ ), $Z=5.47, p<.05, r=.61$, onetailed. H2o was rejected. A Wilcoxon Signed-ranks test indicated higher scores for Knowledge of CRT $(\mathrm{Mdn}=51.5)$ than for Value (about meeting needs) of Different Communities (Mdn = 34), $\mathrm{Z}=5.41, \mathrm{p}<.05, \mathrm{r}=.60$, one-tailed. H3o was rejected. A Wilcoxon Signed-ranks test indicated higher scores for Value/Importance of CRT $(\mathrm{Mdn}=55)$ than for Value (about meeting needs) of Different Communities (Mdn = 34), $\mathrm{Z}=5.53, \mathrm{p}<.05, \mathrm{r}=.62$, one-tailed. H4o was rejected. A Wilcoxon Signed-ranks test indicated higher scores for Use of CRT $(\mathrm{Mdn}=51)$ than for Practice (meeting needs) of Different Communities (Mdn = 29.5), $\mathrm{Z}=5.50, \mathrm{p}<.05, \mathrm{r}=.61$, one-tailed. H5o was rejected. A Wilcoxon Signed-ranks test indicated higher scores for Prep/Skills for CREP (Mdn = 48) than for KSAs (for meeting needs) of Different Communities $(\mathrm{Mdn}=28), \mathrm{Z}=5.45, \mathrm{p}<.05, \mathrm{r}=.61$, one-tailed. H6o was rejected.

We found no significant between group differences in subscale and overall scores by sector, degree level taught, and gender. The sample was too small to examine differences by other demographic variables. Thus, we did not reject null hypotheses H7o, H8o, or H9o. 
Table 4

Descriptive Statistics for Subscale Summed Scores - Pilot and Main Study Combined

\begin{tabular}{|c|c|c|c|c|c|c|c|c|c|c|}
\hline & $\begin{array}{l}\text { Sec 1: } \\
\text { Know- } \\
\text { ledge } \\
\text { about } \\
\text { CRT }\end{array}$ & $\begin{array}{l}\text { Sec 2: } \\
\text { Val/ } \\
\text { imp of } \\
\text { CRT }\end{array}$ & $\begin{array}{l}\text { Sec 3: } \\
\text { Use } \\
\text { of } \\
\text { CREP }\end{array}$ & $\begin{array}{l}\text { Sec 4: } \\
\text { Prep/ } \\
\text { skills to } \\
\text { use } \\
\text { CREP }\end{array}$ & $\begin{array}{l}\text { Sec 5: } \\
\text { Know- } \\
\text { ledge } \\
- \text { diff } \\
\text { cmts }\end{array}$ & $\begin{array}{l}\text { Sec 5: } \\
\text { Val - } \\
\text { diff } \\
\text { cmts }\end{array}$ & $\begin{array}{l}\text { Sec 5: } \\
\text { Pract - } \\
\text { diff } \\
\text { cmts }\end{array}$ & $\begin{array}{l}\text { Sec 5: } \\
\text { Diff } \\
\text { cmts } \\
\text { KSAs }\end{array}$ & $\begin{array}{l}\text { Sec } \\
\text { Overall }\end{array}$ & 5: \\
\hline $\begin{array}{l}\text { N Valid: } \\
\mathrm{N}\end{array}$ & 51 & 48 & 47 & 42 & 41 & 40 & 40 & 40 & 40 & \\
\hline Missing: & 35 & 38 & 39 & 44 & 45 & 46 & 46 & 46 & 46 & \\
\hline $\begin{array}{l}\text { Possible } \\
\text { points: }\end{array}$ & 60.00 & 60.00 & 60.00 & 60.00 & 35.00 & 35.00 & 35.00 & 35.00 & 140.00 & \\
\hline Mean: & 48.78 & 52.06 & 48.60 & 47.50 & 29.24 & 31.15 & 29.85 & 29.33 & 119.53 & \\
\hline Median: & 50.00 & 55.00 & 51.00 & 48.00 & 29.00 & 34.00 & 29.50 & 28.00 & 119.00 & \\
\hline Mode: & 60.00 & 60.00 & 60.00 & 60.00 & 35.00 & 35.00 & 35.00 & 28.00 & 140.00 & \\
\hline Std. Dev: & 11.58 & 9.49 & 10.66 & 10.18 & 4.75 & 5.49 & 5.27 & 4.20 & 15.06 & \\
\hline Range: & 44.00 & 48.00 & 48.00 & 37.00 & 20.00 & 28.00 & 28.00 & 15.00 & 56.00 & \\
\hline
\end{tabular}

\section{Discussion/Conclusions}

The purpose of the study was to create and pilot test an assessment instrument for online faculty members designed to measure culturally responsive teaching knowledge and culturally responsive educational practices in teaching and advising students of color, military students, LGBTQ students, religious minority students, and international students. The two-phase pilot test revealed evidence of strong face validity, content validity, and construct validity. The pilot test also revealed evidence of high internal consistency reliability and good interrater agreement in terms of intra-class correlations. The resultant instrument is ready to be used in a large-scale assessment of culturally responsive teaching knowledge and culturally responsive educational practices in teaching and advising students of color, military students, LGBTQ students, religious minority students, and international students.

The purpose was also to examine the level of and differences in cultural responsiveness knowledge and culturally responsive practices. The results revealed significantly higher scores for Value/Importance of CRT vs. Knowledge of CRT, indicating that while the online faculty in the sample recognized the need for culturally responsive teaching, they also recognize that their knowledge may fall short addressing this need. These findings are consistent with recent imperatives for ensuring that instructors recognize the importance of identity, language, and culture in shaping how students learn (Guerra, 2006) and informing their pedagogy (Banks, 2016). A larger sample might reveal significant within-group differences between the other subscale scores for sections $1-4$ on the instrument. 
The results also indicated significantly higher scores for Knowledge of CRT vs. Knowledge (about meeting needs) of Different Communities; for Knowledge of CRT vs. Value (about meeting needs) of Different Communities; for Value/Importance of CRT vs. Value (about meeting needs) of Different Communities; for Use of CRT vs. Practice (meeting needs) of Different Communities; and. for Prep/Skills for CREP vs. Knowledge/Skills/Abilities (for meeting needs) of Different Communities. The unequal number of items for Section 5-a limitation of the instrument in its current form renders these findings questionable; further analysis can serve to equilibrate scores in Section 5 and its subsections with the other sections in order to have more valid comparisons between sections.

Other limitations also affect the utility of the findings. Mann Whitney $U$ test did not reveal significant differences in subscale scores or overall score by sector, degree level taught, or gender. The small sample size despite extensive recruitment of participants, the need to discard multiple surveys that were missing responses in a given subsection, and the lack of adequate statistical power for between-group comparisons, are other important limitations. Further outreach may help to identify new population sources. Replication is needed with a large, national sample across educational sectors and levels.

The findings are consistent with Culturally Responsive Pedagogy or Culturally Responsive Teaching (Banks, 2008; Gay, 2010, 2013; Ginsberg \& Wlodkowski, 2009; Gurin et al., 2002; Ladson-Billings, 1995; Villegas \& Lucas, 2002); creating equal opportunity for academic success for students from diverse cultural backgrounds (Banks, 2008; Gay, 2010, 2013; Ginsberg \& Wlodkowski, 2009; Gurin et al., 2002; Ladson-Billings, 1995) in the online higher education environment, and acknowledging students' diverse backgrounds, prior knowledge, learning preferences, and experiences to enhance the process of teaching and learning (Siwatu, 2007) online. Higher education faculty who teach online would benefit from onboarding training, professional development, and mentoring specifically targeted to improving their ability to meet these best practices for instructing diverse learners in the online environment. The findings are also consistent with the need for developing additional competence in instruction and assessment (Banks, 2008; Gay, 2010; Ginsberg \& Wlodkowski, 2009; Gurin et al., 2002; Ladson-Billings, 2008) for online higher education faculty. Targeted onboarding training, professional development, and mentoring can assist faculty who teach online with increasing their competence in instruction and assessment in the online environment. Acknowledging, valuing, and using students' cultural backgrounds and cultural identities is essential for building environments optimal for learning (Arminio et al., 2016; Gay, 2010; Ginsberg \& Wlodkowski, 2009; Gurin et al., 2002; Guerra, 2016; Mutakabbir \& Nuriddin, 2016; Nieto, 1999; Wood \& Palmer, 2016) in the online higher education environment.

The findings partially address knowledge gaps about the culturally responsive teaching knowledge and practices of majority online faculty members regarding the extent to which online faculty members are aware of these issues and consider them in their work, the extent to which they value and apply culturally responsive practices, what skills they think they have, and what skills they perceive they are lacking. The sample size was insufficient to address the knowledge gap about whether cultural responsiveness knowledge and culturally responsive practices differ by education sector and degree level taught. 
The findings support the need to provide adequate professional development and support for online faculty who teach diverse students. Faculty who teach online who understand and value culturally responsive pedagogy and have the knowledge and skills to implement best practices in meeting the needs of diverse learners will enhance both teaching and learning. Culturally responsive knowledges and practice are particularly important as online programs are becoming ubiquitous across traditional institutions of higher education and their core faculty is teaching an increasingly diverse student body. The findings, although limited, have implications for institutional leaders and administrators to develop and support their online instructors teaching asynchronously across multiple geographic locations and diverse cultural backgrounds. The findings support the need for online faculty training, professional development, mentoring, and support.

A quantitative descriptive comparative design was applied to: (a) create and pilot test an assessment for online faculty to measure culturally responsive teaching knowledge (CRT) and culturally responsive educational practices (CREP) of online higher education faculty; (b) describe CRT knowledge, value, and CREP; and (c) examine differences in knowledge and practices. Internal consistency reliability was high for all subscales. The pilot rounds revealed strong face and content validity. Campbell-Fiske multitrait-multimethod matrix generated evidence of construct validity. Within-group comparisons of subscale scores revealed significantly higher scores for Value/Importance of CRT vs. Knowledge of CRT; for Knowledge of CRT vs. Knowledge (about meeting needs) of Different Communities; for Knowledge of CRT vs. Value (about meeting needs) of Different Communities; for Value/Importance of CRT vs. Value (about meeting needs) of Different Communities; for Use of CRT vs. Practice (meeting needs) of Different Communities; and. for Prep/Skills for CREP vs. Knowledge/Skills/Abilities (for meeting needs) of Different Communities. Further research is needed to examine differences in subscale scores or overall score by sector, degree level taught, and gender. The results have important implications for faculty training, professional development, mentoring, and support.

\section{About the Authors}

Keri L. Heitner, Ph.D., is a research psychologist and writer focusing on service delivery research and program development in education, diversity, skills and training, health, mental health, and human services. Dr. Heitner designs and implements needs assessments and program and project evaluations and conducts research on diversity-related topics, ethical and gender issues, and business/entrepreneurship. Dr. Heitner conducted this study as a research fellow for the Center for Educational and Instructional Technology Research at the School of Advanced Studies, University of Phoenix. She can be reached at keri.heitner@gmail.com.

Miranda Jennings, Ph.D. is a Professor and Dissertation Chair in the School of Education at Northcentral University. Her research interests include online education and educational technology. She is also interested in the creation of online surveys and technology self-efficacy.

The authors would like to acknowledge to Dr. Mansureh Kebritchi, the director of the Center for Educational and Instructional Technology Research, School of Advanced Studies, University of Phoenix, for her support of the research project. 


\section{References}

Allen, E., \& Seaman, J. (2011). Going the distance: Online education in the United States. Babson Survey Research Group. Retrieved from http://www.onlinelearningsurvey.com/ reports/goingthedistance.pdf

Allen, E., \& Seaman, J. (2013). Changing the course: Ten years of tracking online education in the United States. Babson survey research group. Retrieved from http:// www.onlinelearningsurvey.com/reports/changingcourse.pdf

Baldwin, T. A. (2015). Culturally responsive pedagogy: A transformative tool for CCCU educators in multicultural classrooms. Christian Education Journal, 12(1), 97. Retrieved from http://journals.biola.edu/ns/cej/

Banks, J. A. (2008). An introduction to multicultural education (4th ed.). Boston, MA: Allyn and Bacon.

Arminio, J., Grabosky, T. K., \& Lang, J. (2016). Student veterans and service members in higher education. New York, NY: Routledge.

Banks, J. A. (2016). Cultural diversity and education (6th ed.). New York, NY: Routledge.

Barker, M. J. (2011). Racial context, currency and connections: Black doctoral student and white advisor perspectives on cross-race advising. Innovations in Education and Teaching International, 48(4), 387-400. doi:10.1080/14703297.2011.617092

Blake-Beard, S., Bayne, M. L., Crosby, F. J., \& Muller, C. B. (2011). Matching by race and gender in mentoring relationships: Keeping our eyes on the prize. Journal of Social Issues, 67(3), 622-643. doi:10.1111/j.1540-4560.2011.01717.x

Cate, C. A., \& Albright, G. (2014). Supporting student veterans: Utilizing game-based role-plays with virtual humans to build military cultural competency and helping behaviors in faculty and staff. Online Learning: Official Journal of the Online Learning Consortium, 19(1). Retrieved from http://olj.onlinelearningconsortium.org/index.php/jaln

Campbell, D. T., \& Fisk, D. W. (1959). Convergent and discriminant validation by the multitraitmultimethod matrix. Psychological Bulletin, 56(2), 81-105.

Felder, P. (2010). On doctoral student development: Exploring faculty mentoring in the shaping of African American doctoral student success. Qualitative Report, 15(2), 455-474. Retrieved from http://www.nova.edu/ssss/QR/QR15-2/felder.pdf

Felder, P. P., \& Barker, M. J. (2013). Extending Bell's concept of interest convergence: A framework for understanding the African American doctoral student experience. International Journal of Doctoral Studies, 8, 1-20. Retrieved from http://ijds.org/Volume8/IJDSv8p001-020Felder0384.pdf 
Felder, P., \& Barker, M. J. (2014). African Americans and the doctoral experience: A case comparison through Bell's interest convergence. Journal of Progressive Policy and Practice, 2(1), 79-100.

Ford, K., \& Vignare, K. (2014). The evolving military learner population: A review of the literature. Online Learning: Official Journal of the Online Learning Consortium, 19(1). Retrieved from http://olj.onlinelearningconsortium.org/index.php/jaln

Gay, G. (2010). Culturally responsive teaching: Theory, research, and practice. New York, NY: Teachers College Press.

Gay, G. (2013). Teaching to and through cultural diversity. Curriculum Inquiry, 43(1), 48-70.

Gleeson, T. D., \& Hemmer, P. A. (2014). Providing care to military personnel and their families: How we can all contribute. Academic Medicine: Journal of the Association of American Medical Colleges, 89(9), 1201-1203. doi:10.1097/ACM.0000000000000368

Guerra, J. C. (2006). Language, culture, identity and citizenship in college classrooms and communities. New York, NY: Routledge.

Gurin, P., Day, E. L., Hurtado, S., \& Gurin, G. (2002). Diversity and higher education: Theory and impact on educational outcomes. Harvard Educational Review, 7(3), 330-366. Retrieved from https://igr.umich.edu/files/igr/Diversity\%20and\%20Higher\%20Education.pdf

Ginsberg, M. B., \& Wlodkowski, R. J. (2009). Diversity and motivation: Culturally responsive teaching in college. San Francisco, CA: Jossey-Bass.

Han, H. S., Vomvoridi-Ivanović, E., Jacobs, J., Karanxha, Z., Lypka, A., Topdemir, C., \& Feldman, A. (2014). Culturally responsive pedagogy in higher education: A collaborative self-study. Studying Teacher Education, 10(3), 290-312.

doi:10.1080/17425964.2014.958072

Harper, S. R., \& Quaye, S. J. (Eds.). (2010). Student engagement in higher education: Theoretical perspectives and practical approaches for diverse populations. New York, NY: Routledge.

Heitner, K. L., \& Sherman, K. C. (2013). The role of career colleges: Implications for serving racial and ethnic minority students. Journal of Psychological Issues in Organizational Culture, 3(S1), 78-103. doi:10.1002/jpoc.21098

Jabbar, A., \& Hardaker, G. (2013). The role of culturally responsive teaching for supporting ethnic diversity in British university business schools. Teaching in Higher Education, 18(3), 272-284. doi:10.1080/13562517.2012.725221 
Ladson-Billings, G. (1995). Toward a theory of culturally relevant pedagogy. American Educational Research Journal, 32(3), 465-491. Retrieved from http:// www.hs.iastate.edu/wpcontent/uploads/2011/01/Toward_a_Theory_of_Culturally_Relevant_Pedagogy.pdf

Mutakabbir, Y. T., \& Nuriddin, A. T. (2016). Religious minority students in higher education. New York, NY: Routledge.

Nieto, S. (1999). The light in their eyes: Creating multicultural learning opportunities. New York, NY: Teachers College.

Olesova, L., Yang, D., \& Richardson, J. C. (2011). Cross-cultural differences in undergraduate students' perceptions of online barriers. Journal of Asynchronous Learning Networks, 15(3), 68-80. Retrieved from http://olj.onlinelearningconsortium.org/index.php/jaln

Sadykova, G., \& Dautermann, J. (2009). Crossing cultures and borders in international online distance higher education. Journal of Asynchronous Learning Networks, 13(2), 89-114. Retrieved from http://olj.onlinelearningconsortium.org/index.php/jaln

Starr-Glass, D. (2011). Military learners: Experience in the design and management of online learning environments. Journal of Online Learning and Teaching, 7(1), 147-158. Retrieved from http://jolt.merlot.org/vol7no1/starr-glass_0311.pdf

Starr-Glass, D. (2014). Rules of engagement: Considering good policy and practice with online military learners. Online Learning: Official Journal of the Online Learning Consortium, 19(1). Retrieved from http://olj.onlinelearningconsortium.org/index.php/jaln

Steele, J. L., Salcedo, N., \& Coley, J. (2010). Service members in school: Military veterans' experiences using the Post-9/11 GI Bill and pursuing postsecondary education. Retrieved from http://www.rand.org/pubs/monographs/MG1083.html

Villegas, A. M., \& T. Lucas. (2002). Preparing culturally responsive teachers: Rethinking the curriculum. Journal of Teacher Education, 53(20), 20-32.

doi:10.1177/0022487102053001003

Wood, J. L., \& Palmer, R. T. (2016). Black men in higher education. New York, NY: Routledge. 


\section{Appendices}

\section{SurveyMonkey Pro Questionnaire (for Pilot Test and Main Study)}

[Respondents who click "Yes" on the informed consent page in SurveyMonkey will be directed to the qualifying questions.]

Thank you for consenting to participate in the research study. Please respond to the following qualifying question

S1: In the last two years, have you taught at least five online classes at the undergraduate or graduate level? The five classes may consist of having taught the same course multiple times or five different courses, or any combination thereof. Please do not count independent study or dissertation classes taught one-on-one.

[Respondents who answer "No" to S1 will be thanked for their interest and informed that they do not meet the criteria for the study. Respondents who answer Yes to S1 will be directed to continue the survey.]

Withdrawal code: Before we begin, please enter a code name below that you may use in the event that you decide to withdraw from the study. Record the code name for future use, should you decide to request withdrawal, as per the information in the informed consent document.

Code name for withdrawal purposes:

\section{Background and Instructions:}

According to Gay (2010), culturally responsive teaching is "using the cultural knowledge, prior experiences, frames of reference, and performance styles of ethnically diverse students to make learning encounters more relevant to and effective for them" (p. 31). In the current study, we are extending the definition to include diversity in terms of class, religion, sexual orientation, military status, age, etc.

The following questions and items will allow us to measure the extent to which online faculty consider, value, and address culturally responsive teaching in their work. Questions pertaining to each of these elements are comprised of several items corresponding to each area of focus. Questions also pertain to what skills online faculty think they have, and what skills they perceive they are lacking. The final section contains demographic questions about your education sector and teaching experience, as well as other demographic questions, the responses to which are optional.

Gay, G. (2010). Culturally responsive teaching: Theory, research, and practice. New York, NY: Teachers College Press.

\section{Section 1: Knowledge about culturally responsive teaching.}

Question 1/Items 1.1-1.12. Please rate your current knowledge of the following culturally responsive tenets and approaches, using the following scale: 1-Poor; 2- Fair; 3- Good; 4-Very Good; 5-Excellent

\subsection{Recognizing the importance of cultural diversity in online learning.}


1.2. Viewing cultural differences in the online classroom as assets.

1.3. Creating caring online learning communities that value diverse cultures and heritages.

1.4. Using knowledge of diverse cultures and communities to guide curriculum development for online courses.

1.5. Using knowledge of diverse cultures and communities to guide online classroom climates.

1.6. Using knowledge of diverse cultures and communities to guide online instructional strategies.

1.7. Using knowledge of diverse cultures and communities to guide relationships with online students.

1.8. Challenging stereotypes, prejudices, racism, sexism, and other forms of intolerance, injustice, and oppression that manifest in the online classroom.

1.9. Acting as a change agent for social justice and academic equity in online education.

1.10. Mediating power imbalances (disparities in who has more perceived or actual power) in online classrooms based on race, culture, ethnicity, class, sexual orientation, military status, age, etc.

1.11. Accepting cultural responsiveness as endemic to educational effectiveness in all areas of learning for diverse online students.

1.12. "Using the cultural knowledge, prior experiences, frames of reference, and performance styles of ethnically diverse students to make learning encounters more relevant to and effective for them” (Gay, 2010, p. 31).

\section{Section 2: Value/importance of culturally responsive teaching.}

Question 2/Items 2.1-2.12. Please rate your opinion of the importance of the following items to your online teaching, using the following scale: 1-Not at all important; 2- Slightly important; 3Somewhat important; 4-Very important; 5-Extremely important

2.1. Recognizing the importance of cultural diversity in online learning.

2.2. Viewing cultural differences in the online classroom as assets.

2.3. Creating caring online learning communities that value diverse cultures and heritages.

2.4. Using knowledge of diverse cultures and communities to guide curriculum development for online courses.

2.5. Using knowledge of diverse cultures and communities to guide online classroom climates.

2.6. Using knowledge of diverse cultures and communities to guide online instructional strategies.

2.7. Using knowledge of diverse cultures and communities to guide relationships with online students.

2.8. Challenging stereotypes, prejudices, racism, sexism, and other forms of intolerance, injustice, and oppression that manifest in the online classroom.

2.9. Acting as a change agent for social justice and academic equity in online education. 
2.10. Mediating power imbalances (disparities in who has more perceived or actual power) in online classrooms based on race, culture, ethnicity, class, religion, sexual orientation, military status, age, etc.

2.11. Accepting cultural responsiveness as endemic to educational effectiveness in all areas of learning for diverse online students.

2.12. "Using the cultural knowledge, prior experiences, frames of reference, and performance styles of ethnically diverse students to make learning encounters more relevant to and effective for them” (Gay, 2010, p. 31).

\section{Section 3: Use of culturally responsive educational practices.}

Question 3/Items 3.1-3.12. Please rate the extent to which you use the following practices in your online teaching, using the following scale: 1-Never; 2- Rarely; 3- Occasionally; 4Frequently; 5-All the time.

3.1. Recognizing the importance of cultural diversity in online learning.

3.2. Viewing cultural differences in the online classroom as assets.

3.3. Creating caring online learning communities that value diverse cultures and heritages.

3.4. Using knowledge of diverse cultures and communities to guide curriculum development for online courses.

3.5. Using knowledge of diverse cultures and communities to guide online classroom climates.

3.6. Using knowledge of diverse cultures and communities to guide online instructional strategies.

3.7. Using knowledge of diverse cultures and communities to guide relationships with online students.

3.8. Challenging stereotypes, prejudices, racism, sexism, and other forms of intolerance, injustice, and oppression that manifest in the online classroom

3.9. Acting as a change agent for social justice and academic equity in online education.

3.10. Mediating power imbalances (disparities in who has more perceived or actual power) in online classrooms based on race, culture, ethnicity, class, sexual orientation, military status, age, etc.

3.11. Accepting cultural responsiveness as endemic to educational effectiveness in all areas of learning for diverse online students.

3.12. "Using the cultural knowledge, prior experiences, frames of reference, and performance styles of ethnically diverse students to make learning encounters more relevant to and effective for them” (Gay, 2010, p. 31).

\section{Section 4: Preparation/skills to use culturally responsive educational practices.}

Question 4/Items 4.1-4.12. Please rate your perceived level of preparation regarding having the requisite knowledge, skills, and abilities to use the following practices in your online teaching, using the following scale: 1-Poor; 2- Fair; 3- Good; 4-Very good; 5-Excellent.

4.1. Recognizing the importance of cultural diversity in online learning. 
4.2. Viewing cultural differences in the online classroom as assets.

4.3. Creating caring online learning communities that value diverse cultures and heritages.

4.4. Using knowledge of diverse cultures and communities to guide curriculum development for online courses.

4.5. Using knowledge of diverse cultures and communities to guide online classroom climates.

4.6. Using knowledge of diverse cultures and communities to guide online instructional strategies.

4.7. Using knowledge of diverse cultures and communities to guide relationships with online students.

4.8. Challenging stereotypes, prejudices, racism, sexism, and other forms of intolerance, injustice, and oppression that manifest in the online classroom.

4.9. Acting as a change agent for social justice and academic equity in online education.

4.10. Mediating power imbalances (disparities in who has more perceived or actual power) in online classrooms based on race, culture, ethnicity, class, sexual orientation, military status, age, etc.

4.11. Accepting cultural responsiveness as endemic to educational effectiveness in all areas of learning for diverse online students.

4.12. "Using the cultural knowledge, prior experiences, frames of reference, and performance styles of ethnically diverse students to make learning encounters more relevant to and effective for them” (Gay, 2010, p. 31).

\section{Section 5: Meeting the needs of different communities of students.}

Question 5/Items 5.1-5.7 - Knowledge. Please rate your agreement with the next set of statements about your knowledge about the approaches identified in the earlier questions, using the following scale: 1-Strongly Disagree; 2- Disagree; 3- Unsure; 4-Agree; 5-Strongly Agree.

5.1. I am knowledgeable about culturally responsive teaching approaches to meet the needs of students from diverse socioeconomic backgrounds.

5.2. I am knowledgeable about culturally responsive teaching approaches to meet the needs of students from diverse racial and ethnic communities.

5.3. I am knowledgeable about culturally responsive teaching to meet the needs of students from diverse international backgrounds.

5.4. I am knowledgeable about culturally responsive teaching approaches to meet the needs of students from diverse religious backgrounds.

5.5. I am knowledgeable about culturally responsive teaching approaches to meet the needs of lesbian, gay, bisexual, transgender, and questioning (LGBTQ) students.

5.6. I am knowledgeable about culturally responsive teaching approaches to meet the needs of students from military backgrounds.

5.7. I am knowledgeable about culturally responsive teaching approaches to meet the needs of students of different generations. 
Question 5/Items 5.8-5.14 - Value. Please rate your agreement with the next set of statements about your value of the use of the approaches identified in earlier questions, using the following scale: 1-Strongly Disagree; 2- Disagree; 3- Unsure; 4-Agree; 5-Strongly Agree.

5.8. I value the use of culturally responsive teaching approaches to meet the needs of students from diverse socioeconomic backgrounds.

5.9. I value the use of culturally responsive teaching approaches to meet the needs of students from diverse racial and ethnic communities.

5.10. I value the use of culturally responsive teaching to meet the needs of students from diverse international backgrounds.

5.11. I value the use of culturally responsive teaching approaches to meet the needs of students from diverse religious backgrounds.

5.12. I value the use of culturally responsive teaching approaches to meet the needs of LGBTQ students.

5.13. I value the use of culturally responsive teaching approaches to meet the needs of students from military backgrounds.

5.14. I value the use of culturally responsive teaching approaches to meet the needs of students of different generations.

Question 5/Items 5.15-5.21 - Practice. Please rate your agreement with the next set of statements about your practice of the approaches identified in earlier questions, using the following scale: 1-Strongly Disagree; 2- Disagree; 3- Unsure; 4-Agree; 5-Strongly Agree.

5.15. I practice culturally responsive teaching to meet the needs of students from diverse socioeconomic backgrounds.

5.16. I practice culturally responsive teaching approaches to meet the needs of students from diverse racial and ethnic communities.

5.17. I practice culturally responsive teaching to meet the needs of students from diverse international backgrounds.

5.18. I practice culturally responsive teaching approaches to meet the needs of students from diverse religious backgrounds.

5.19. I practice culturally responsive teaching approaches to meet the needs of LGBTQ students.

5.20. I practice culturally responsive teaching approaches to meet the needs of students from military backgrounds.

5.21. I practice culturally responsive teaching approaches to meet the needs of students of different generations.

Question 5/Items 5.22-5.28 - Knowledge, Skills, Abilities (KSAs). Knowledge (K) is familiarity with the subject matter. Skills (S) are the level of competency, proficiency, or expertise. Abilities (A) are capacities to perform a task or activity. Please rate your agreement with the next set of statements about your knowledge, skills, and abilities needed to use the approaches identified in earlier questions, using the following scale: 1-Strongly Disagree; 2Disagree; 3- Unsure; 4-Agree; 5-Strongly Agree. 
5.22. I have the KSAs needed to practice culturally responsive teaching to meet the needs of students from diverse socioeconomic backgrounds.

5.23. I have the KSAs needed to practice culturally responsive teaching approaches to meet the needs of students from diverse racial and ethnic communities.

5.24. I have the KSAs needed to practice culturally responsive teaching to meet the needs of students from diverse international backgrounds.

5.25. I have the KSAs needed to practice culturally responsive teaching approaches to meet the needs of students from diverse religious backgrounds.

5.26. I have the KSAs needed to practice culturally responsive teaching approaches to meet the needs of LGBTQ students.

5.27. I have the KSAs needed to practice culturally responsive teaching approaches to meet the needs of students from military backgrounds.

5.28. I have the KSAs needed to practice culturally responsive teaching approaches to meet the needs of students of different generations.

\section{Section 6: Teaching experience and demographic questions D1-D13.}

D1. In which higher education sector or sectors do you most frequently teach online? (check all that apply)

Not-for-profit - public (e.g., community college, state or city college or university)

_Not-for-profit - private (independent non-profit colleges and universities)

_For-profit educational institution (of any kind)

_Career College or technical school

D2: What is the level of education you have taught online? (check all that apply)

Undergraduate - 2-year

Undergraduate - 4-year

_Graduate - Master's

_Graduate - Doctoral

D3: How many years have you been teaching on ground at the postsecondary level (i.e., in a brick and mortar classroom)?

- $2-5$ years

6-10 years

_ More than 10 years

D4: How many years have you been teaching online at the postsecondary level?

2-5 years

6-10 years

_More than 10 years

D5: How many classes have you taught fully online? A class is one section of an online course. You can count each single class of an online course you have taught multiple times. Please do not count independent study or dissertation classes taught one-on-one. 
5-10 classes

11-15 classes

More than 15 classes

D6: Do you identify as a member of a racial, ethnic, or linguistic minority group:

Yes

No

D7: Do you identify as lesbian, gay, bisexual, transgender, or questioning (LGBTQ)?

Yes

- No

D8: Are you currently or have you been a member of the U.S. Armed Forces?

Yes

No

D9: Has an immediate family member (parent, child, sibling, or spouse) currently or previously been a member of the U.S. Armed Forces?

Yes

No

D10: What is your age group?

Under 25

25-39

40-54

55 or older

D11: Do you identify as:

Male

Female

_Other (please indicate):

D12: Do you identify as a member of a religious minority group?

Yes

No

D13: Did you grow up in the United States or arrive at age 18 or older?

Grew up in the United States

_ Came to the United States at age 18 or older.

Thank you for participating in the study. If you know of other faculty who teach online at the postsecondary level who might be interested in participating, please share the study announcement or the survey URL with them. You may also contact me to learn about the results of the study, at -------. 